\title{
Well-being and mental stress in the Population Study of Women in Gothenburg, Sweden: Cohort comparisons from 1980 to 2016 of 36-year trends and socioeconomic disparities in 38-and 50-year old women
}

Maria Waller ( $\triangle$ maria.waller@gu.se )

Sahlgrenska Academy https://orcid.org/0000-0001-6871-1667

Lauren Lissner

Sahlgrenska Academy,

Dominique Hange

Sahlgrenska Academy

Valter Sundh

Sahlgrenska Academy

Ann Blomstrand

Sahlgrenska Academy

Cecilia Björkelund

Sahlgrenska Academy

\section{Research article}

Keywords: Well-being, mental stress, socioeconomic position, women, trends over time, cohort comparisons.

Posted Date: August 26th, 2020

DOI: https://doi.org/10.21203/rs.3.rs-60007/v1

License: (c) (i) This work is licensed under a Creative Commons Attribution 4.0 International License.

Read Full License 
Well-being and mental stress in the Population Study of Women in Gothenburg,

Sweden: Cohort comparisons from 1980 to 2016 of 36-year trends and socioeconomic disparities in 38-and 50-year old women

Waller $\mathrm{M}^{1}$, Lissner $\mathrm{L}^{2}$, Hange $\mathrm{D}^{1}$, Sundh $\mathrm{V}^{2}$, Blomstrand $\mathrm{A}^{1}$, Björkelund $\mathrm{C}^{1}$

${ }^{1}$ Primary Health Care, School of Public Health and Community Medicine, Institute of Medicine,

Sahlgrenska Academy, University of Gothenburg, Gothenburg, Sweden

${ }^{2}$ Nutritional Epidemiology, School of Public Health and Community Medicine, Institute of Medicine, Sahlgrenska Academy, University of Gothenburg, Gothenburg, Sweden

Corresponding author: Maria Waller, Primary Health Care, School of Public Health and Community Medicine, Institute of Medicine, Sahlgrenska Academy, University of Gothenburg , Box 454, 40530 Gothenburg, Sweden 


\begin{abstract}
Background Women`s life situations has dramatically changed in recent decades. Self-reported health in women has been reported significantly lower than in men in all age groups 18-70 years. In Sweden, the National Public Health Report 2005 showed that stressful work environments have become more common especially for women. The purpose of the study was to monitor trends in well-being and mental stress in the populations of 38- and 50-year-old women and to examine associations with socioeconomic position (SEP).
\end{abstract}

Subjects Population-based cohorts of 38- and 50-year-old women as a part of the Prospective Population Study of Women in Gothenburg were invited in 1980, 2004 and 2016 to health examinations, with similar protocols on each occasion

Methods Cohort comparisons between three representative samples of 38- and 50-year-old women. Well-being (scale 1-7) and perceived mental stress (scale 1-6) based on questionnaires were the main outcomes studied in relation to time. Socioeconomic position (SEP) based on sociooccupational group, i.e. occupational and educational level combined were examined as correlates well-being and mental stress at different points in time.

Results Perception of good well-being increased in 50-year-old women between 1980 to 2016, but no significant time trends were seen in 38-year-old women. Perception of high mental stress increased between 1980 and 2016, for both 38-and 50-year-old women. Belonging to a low sociooccupational group was associated with lower perceived well-being in 1980 but not in 2016 . Belonging to a low socio-occupational group was not associated with perceived mental stress at any examination. 
Conclusions Contemporary women of today have generally higher perceptions of well-being and higher mental stress regardless of belonging to low or high socio-occupational group. Associations between poor well-being and belonging to a low socio-occupational group that were observed in 1980 disappeared in 2016.

Trial registration The Prospective Population Study of Women in Gothenburg, Sweden was approved by the ethics committee of University of Gothenburg (Dnr 65-80; 0̈564-03; 258-16). The studies comply with the Declaration of Helsinki and informed consent has been obtained from the subjects.

\section{Key words}

Well-being, mental stress, socioeconomic position, women, trends over time, cohort comparisons. 


\section{Background}

Societal changes in recent decades, have affected women`s life situations dramatically. In a large WHO survey in 2004, data from 57 countries showed that self-reported health in women was significantly lower than in men in all age groups $18-70$ years (1). In Sweden, improvements in women's health have been documented by in the National Public Health Report from 2005 (2), which showed that women's life expectancy has increased by 2 years since 1990 . The report also showed that stressful work environments have become more common especially for women. This is most prevalent in workplaces in the public sector concerning care and healthcare, nursing, and teaching, all of which are well-known to be women-dominated. In Gothenburg, Sweden, an increasing proportion of the female population state that they experience anxiety and mental stress, around $75 \%$ in 2004, compared to $25 \%$ in the 1960 's (3). During the corresponding time period it was reported that the stress-levels in 50-year-old men were unchanged and continuously low, $17 \%(4)$.

Perceived health, well-being and mental stress are closely related factors (5). Differences are still seen between men and women with regard to their health situation (6). Further, chronic diseases such as cardiovascular disease and diabetes are more common among less educated, both concerning women and men. Social disparities in life expectancy increased in 1986 to 2007 in Sweden, especially among women (6).

In 1974, Sweden was the first Nordic country to introduce the law on parental insurance for both women and men (7). This made it more possible for women to return to work outside the home after childbirth and parental leave. Further, women's life situation has changed markedly in recent decades. For example, in Sweden, the mean age that women choose to give birth to their first 
child has risen from 24 years in 1980 to 28.5 years in 2006 and 28.6 in 2016 (8). These changes have resulted in a transformation of the Swedish family in modern society (7).

A generation shift concerning women's perceived mood has been observed during the latest decades. In earlier generations of middle-aged women, family conditions were associated with women's perceived mood (9). In contrast, for later generations of middle-aged women, the work situation was most significantly associated with their perceptions of mood (9).

Women's work situation is also greatly changed (10). Increased educational opportunities and changing economic resources have affected employment possibilities for middle-aged women, resulting in changes in their employment rates which were less than $50 \%$ in the 1970 s. The rates increased to $75 \%$ full time ( $\geq 35 \mathrm{~h} /$ week) in 2016 , compared to $92 \%$ among men. (11).

In the Prospective Population Study of Women in Gothenburg, three population-based samples of middle-aged women (38- and 50-year-olds) have participated in physical examinations with questionnaires on lifestyle in order to document secular trends in cardiovascular health indicators (12). The representative cohorts described their well-being with the same questionnaires in 1980, 2004 and 2016, respectively. Several cardiovascular risk factors related to lifestyle, i.e. smoking, blood lipid levels, and blood pressure levels, were improved in the middle-aged women in the latest decades (13). A study concerning association between physical activity and well-being showed associations between high physical activity levels and increased well-being in women (14). Trends concerning well-being in middle-aged women have also been studied in other populations (15). However, relationships between socioeconomic position, well-being and perceived mental stress have been studied less frequently, and it is not known whether the trends are uniform in different socioeconomic groups of women over time. 


\section{Methods}

\section{Aim}

The aim of this study was to examine trends in well-being and perceived mental stress and the importance of socioeconomic position (SEP) in the populations of 38- and 50-year-old women in 1980, 2004 and 2016, respectively.

\section{Design and setting}

From the Population Study of Women in Gothenburg (12), we retrieved data on population-based representative samples of 38- and 50-year-old women who were examined in 1980, 2004 and in 2016, respectively (Figure 1). The study population in $1980(n=477)$ comprised 38-year-old women born in 1942 ( $n=122)$ and 50-year-old women born in $1930(n=355)$. The study population in 2004 $(n=500)$ consisted of 38-year-old women who were born in $1966(n=207)$ and the 50-year-old women were born in $1954(n=293)$. The study population in $2016(n=573)$ included 38-year-old women born in 1978 ( $n=263)$ and 50-year-old women born in 1966 (n=310).

\section{Well-being}

Before taking part in the examination at the study premises, the participants were asked to answer a questionnaire on current well-being, family situation, social and educational status.

The question describing general well-being (Figure 2) was: "How do you experience your health situation (well-being)?". The answers were stated on a Likert-type scale from 1 to 7 , where 1 was 
"excellent, couldn't be better" and 7 was "very poor". Good well-being was defined as categories 1 to 3. Poor well-being was defined as categories 4 to 7.

The question originates from the Gothenburg Quality of Life Instrument (GQL instrument) (16) developed in the 1960's, based on WHO's definition of health (17). This question was evaluated in a study (18) and shown to have high reliability. Self-estimated well-being reflected both physical and psychological well-being (18). A further evaluation of this well-being indicator was done for the present study. 1992 was the first time in the Population Study of Women examinations that the SF-36 and the original well-being indicator were used simultaneously. Coefficient of 0.69 between these two general well-being questions indicated high relative validity.

\section{Mental stress}

The women were asked to identify level of perceived mental stress based on a questionnaire item with the same wording throughout all examinations, which were given by the examining study physician. The different categories are shown in Figure 2. This question has been previously evaluated in another study and reliability was confirmed (19). Low mental stress was defined as "never experienced any period of stress", "experienced a period of stress" and " experienced a period of stress during the last 5 years". Moderate and high mental stress was defined as "experienced several periods of stress during the last 5 years", "living under constant stress during the last year" and "living under constant stress during the last 5 years" 
Time

The main exposure variable in this study is time. The different cohorts of women were examined in 1980, 2004 or 2016.

Socioeconomic position

Socioeconomic position (SEP) was defined in terms of the social and economic factors that influence the positions that participants hold within the structure of society (20). For the present study, socioeconomic position (SEP) was based on socio-occupational group, i.e. occupational and educational level combined, as described below.

\section{Socio-occupational group}

The participants reported their occupations and this information was used to categorise them into low, medium and high occupational groups, according to Carlsson's standard occupations grouping system (21). The variable was dichotomised as low and medium-high. This categorisation was accomplished in accordance with the Swedish socioeconomic index (22), a broadly established socio-occupational classification method that includes the individual's educational level (22).

\section{Statistics}

Binary logistic models with outcome variables poor well-being and high stress were used to test for association with exposure factors time, age and SEP. Results are presented as odds ratios (OR) with $95 \%$ confidence intervals $(\mathrm{Cl})$. Associations are considered statistically significant at $p<0.05$. 
Interactions were tested by test of interaction with regard to SEP on time trend in prevalence of poor well-being and high mental stress and presented as ORs.

\section{Results}

Descriptive data

The three different cohorts of 38- and 50-year-old women examined in 1980, 2004 and 2016 are presented in Table 1 regarding number of participants, well-being (poor/good), perceived mental stress level (low/medium-high), socio-occupational level (low/medium-high), smoking (yes/no), $\mathrm{BMI}(<25 / \geq 25)$ and leisure time physical activity (low/high). P values refer to changes over time between the three age cohorts.

Trends in well-being

In 38-year-old women, no significant differences were seen between the three cohorts regarding well-being ( $p=0.69$ ) (Table 1). In 50-year-old women, significant differences were seen between the three cohorts, where the trend showed an increased proportion of women who perceived their well-being as good $(p<0.01)$ (Table 1 ). Table 2 shows results from a fully adjusted model (all women) with time, age and SEP as separate predictors. Significant differences were found $(p<0.00)$, where the lower socio-occupational group had a higher proportion of poor well-being.

Trends in mental stress

Concerning perceived mental stress, a significant trend of increased high mental stress $(p<0.01)$ was seen for both 38- and 50-year-old groups of women (Table 1). Table 2 shows that this was the trend for all women irrespective of age and SEP. 
Importance of SEP

Does SEP modify the association between time and well-being and time and mental stress?

Tests of interactions in all women, examining whether the "risk factor" low socio-occupational group affected the development of well-being over time and of mental stress over time. No significant interactions were found ( $p=0.30$ and 0.32 ). The different SEP groups showed the same development over time concerning well-being and mental stress.

Associations between well-being/mental stress and socioeconomic position

Table 3 shows associations between poor well-being (outcome variable) and low SEP in 1980, 2004 and 2016. In 1980 and 2004 there were significant associations ( $p=0.05$ and $p<0.00$ ) between poor well-being and low SEP but not in 2016. Low socio-occupation as a "risk factor" for poor well-being was greatly attenuated from 1980 to 2016.

Table 3 also shows associations between high mental stress (outcome variable) and low SEP, in 1980, 2004 and 2016. No significant associations were found.

Smoking, BMI and Leisure time physical activity

The trend showed a decreased proportion of women who smoked $(p<0.01)$ from $38 \%$ in 1980 to 9\% in 2016 (concerning 38-year-old women) (Table 1). The proportion of women with overweight and obesity (BMI $\geq 25$ ) increased significantly from $17 \%$ in 1980 to $32 \%$ in 2016 (Table 1). Also the proportion of women with high leisure time physical activity increased significantly from $66 \%$ in 1980 to $93 \%$ in 2016 (Table 1$)$. 


\section{Discussion}

Our results showed that concerning 50-year-old women, the proportion of women who perceived their well-being as good increased significantly from 1980 to 2016. In contrast, no significant differences were seen regarding perception of well-being in 38-year-old women. The percentage of women perceiving high mental stress increased between 1980 and 2016 in both 38-and 50year-old women, yet still there was an increased percentage of well-being among 50-year-old women.

Belonging to a low socio-occupational group was associated with perceived poor well-being in 1980 but not in 2016. In other words, there was a significant trend over time, such that low sociooccupational group as a "risk factor" for poor well-being disappeared from 1980 to 2016. Low socio-occupational group was not a "risk factor" for high perceived mental stress; no associations were found in 1980, 2004 and in 2016.

The strengths of this study are its long duration and the stability of the examination protocols, which have been maintained over a long period of time (36 years). In particular, the similarity of the questionnaires used by the examining physicians allowed us to compare responses over time to the greatest extent possible.

One limitation of the study is that the participation rate declined from 1980 to 2016 (Figure 1), such that $84 \%$ of invited women participated in 1980, compared to $59 \%$ in 2004 and $68 \%$ in 2016. A comparison of participants and non-participants was conducted in 2004 , because of the declining participation rate (13). There were no differences in marital status, hospital admission rate or places of living between participants and non-participants. However, significant differences were observed concerning income and immigration status, with lower mean income and higher proportion of immigrants in the non-participant group. 
It should also be noted that the aim was to examine self-reported well-being, rather than mortality and morbidity endpoints. Other studies have clearly demonstrated that subjective self-rated health is a good predictor of use of health care/mortality (23) and metabolic health (24).

Our results on secular trends in well-being are to a large extent consistent with another longitudinal study from SALLS (Swedish Annual Level of Living Survey) (15). Improved self-rated health was seen in men and women, aged > 48 years between 1980 and 2004, but self-rated health became poorer or was unchanged in those aged 16-47. Moreover, in the MONICA study in northern Sweden (25), women’s self-rated health decreased from 1990 to 2014 whereas men`s self-rated health increased. A French study showed a general decline in health-related quality of life between 1995 and 2016 in the female population (26).

The Helsinki Health Study cohort showed over the 7 years of follow-up that socioeconomic differences in general health (SF-36) had widened among both women and men (27). This was due to a more rapid decline in health in the lower socioeconomic groups.

Several possible explanations for the difference in well-being between 38- and 50-year-old women are possible. Today's 38-year-old women are more likely to have small children, compared to previous generations. This is related to women having a higher average age at the first marriage (28). In 1980, the average age at first marriage was 26. In 2004, the average age at first marriage was 32 and in 2016, the average age was 34. Another possible influence is a higher median age for the first divorce, from 36 years in 1980 to 42 years in 2014 (28). Finally, changes in BMI represent another possible explanation for the difference in well-being between 38- and 50-year-old women observed in the present study. While both cohorts reported changes in smoking and physical activity, only the 38-year-old cohorts had an increasing significant trend showing an increase in the prevalence of $\mathrm{BMI} \geq 25$, whereas in the 50 -year-old cohorts prevalences were unchanged. 


\section{Conclusions}

Women of today perceive both high well-being and high mental stress irrespective of belonging to low or high SEP group. This is in contrast to 1980, when poor well-being was associated with low SEP. Significant secular trends were seen, such that low SEP as "risk factor" for poor well-being disappeared from 1980 to 2016. Perception of high mental stress increased between 1980 and 2016, for both 38-and 50-year-old women, irrespective of SEP. Further studies are needed to explore determinants of women's well-being and mental stress.

\section{Declarations}

\section{Ethics}

The Prospective Population Study of Women in Gothenburg, Sweden was approved by the Ethics committee of University of Gothenburg (Dnr 65-80; Ö564-03; 258-16). The studies comply with the Declaration of Helsinki and informed consent has been obtained from the subjects.

\section{Consent for publication}

Not applicable.

\section{Availability of data and materials}

The datasets used and analysed during the current study are not publicly available due to Swedish law, but are available from the corresponding author on reasonable request. 


\section{Competing interests}

No potential conflicts of interest were reported by the authors.

\section{Funding}

This work was supported by grants from the Swedish Council for Health, Working Life and Welfare - FORTE (EpiLife 2006-1506, WISH 2007-1958) and by grants from the Swedish state under the agreement between the Swedish government and the country councils, the ALF-agreement: GBG68771 and GBG-720201.

\section{Authors'contributions}

MW, CB, LL participated in the design of the study; MW,CB, LL, AB, DH participated in the collection of data in the examinations; MW, $\mathrm{LL}, \mathrm{AB}, \mathrm{VS}, \mathrm{DH}, \mathrm{CB}$ analyzed and interpreted the data; $\mathrm{MW}$ was major contributor in writing the manuscript and $C B, L L, A B, V S, D H$ revised the paper. All authors had full access to all of the study data and take responsibility for the integrity and accuracy of the data. All authors read and approved the final manuscript.

\section{Acknowledgements}

Not applicable. 


\section{References}

1. Hosseinpoor A, Willams S, Amin A, et al. Social determinants of self-reported Health in women and men: Understanding the Role of Gender in Population Health. PLoS ONE. 2012;7:34799.

2. Persson $G$, Danielsson $M$, Rosén $M$, et al. Health in Sweden: The National Public Health Report 2005. Scand J Public Health. 2006;34:3-10.

3. Lissner L, Sjöberg A, Schütze M, Lapidus L, Hulthén L, Björkelund C. Diet, obesity and obesogenic trends in two generations of Swedish women. Eur J Nutr. 2008;48:424-31.

4. Wilhelmsen L, Welin L, Svärdsudd K et al. Secular changes in cardiovascular risk factors and attack rate of myocardial infarction among men aged 50 in Gothenburg, Sweden. Accurate prediction using risk models. J Intern Med. 2008;263:636-643.

5. Tey H C, Archer J, Chang W et al. Mental Well-being mediates the relationship between perceived stress and perceived health. Stress Health. 2015;31:71-77.

6. The National Public Health Report 2009. ISBN:978-91-978065-8-9.

7. Johansson T, Lindgren S, Hellman A. Nya Uppväxtvillkor - Samhälle och Individ I Förändring. (New circumstances for growing up - Society and individual in change). Liber AB. ISBN 978-91-47-09687-9.

8. Socialstyrelsen. Mean age among primiparas by county 1976-2016. ISBN:978-91-7555123-4, tab 1.5. Available from: https://www.socialstyrelsen.se/statistik Accessed 14 Aug 2020.

9. Lundh C, Bengtsson C, Björkelund C. Generation shift in family vs. working conditions as most important influence on women's mood? The Prospective Population Study of Women in Gothenburg, Sweden. Scand J Prim Health Care. 2004;22:101-105.

10. André $\mathrm{M}$, Lissner $\mathrm{L}$, Bengtsson $\mathrm{C}$, et al. Cohort differences in personality in middle-aged women during a 36-year period. Results from the Population Study of Women in Gothenburg. Scand J Public Health. 2010;38:457-464.

11. Statistics Sweden. Available from: https://www.scb.se/hitta-statistik/statistik-efteramne/levnadsforhallanden/levnadsforhallanden/undersokningarna-avlevnadsforhallanden-ulf-silc/pong/tabell-och-diagram/sysselsattning/sysselsattning--flerindikatorer/ Accessed 14 Aug 2020.

12. Bengtsson C, Blohme G, Hallberg L, et al. The study of women in Gothenburg 1968-1969a population study. General design, purpose and sampling results. Act Med Scand. 1973;193:311-318.

13. Björkelund C, Andersson-Hange D, Andersson K, et al. Secular trends in cardiovascular risk factors with a 36-year perspective: observations from 38- and 50-year-olds in the Population Study of Women in Gothenburg. Scand J Prim Health Care. 2008;26:140-146.

14. Blomstrand A, Björkelund C, Ariai N, Lissner L, Bengtsson C. Effects of leisure-time physical activity on well-being among women: a 32-year perspective. Scand J Public Health. 2009;37:706-12.

15. Johansson S, Midlöv P, Sundquist J, et al. Longitudinal trends in good self-rated health: effects of age and birth cohort in a 25-year follow-up study in Sweden. Int J Public Health. 2015;60:363-373.

16. Tibblin G, Tibblin B, Peciva S, et al. "The Göteborg Quality of Life Instrument" - An Assessment of Well-being and Symptoms Among Men born 1913 and 1923. Scand J Prim Health Care. 1990;1:33-38. 
17. Machteld H, Knottnerus A, Green L et al. How should we define health? BMJ. 2011;343:d4163.

18. Sullivan M, Karlsson J, Bengtsson C, et al."The Göteborg Quality of Life Instrument"- A psychometric evaluation of assessments of symptoms and well-being among women in a general population. Scand J Prim Health Care. 1993;11:267-275.

19. Bengtsson C, Hällström T, Tibblin G. Social factors, stress experience, and personality traits in women with ischaemic heart disease, compared to a population sample of women. Acta Med Scand. 1973;549:82-92.

20. Galobardes B, Shaw M, Lawlor DA, et al. Indicators of socioeconomic position (part 1). J Epidemiol Commun H. 2006;60:7-12.

21. Carlsson G. Social mobility and class structure. Lund: Gleerup; 1958.

22. Statistics Sweden. Swedish Socioeconomic Classification. Stockholm: 1982. Available from: https://www.scb.se/dokumentation/klassifikationer-och-standarder/socioekonomiskindelning-sei/Accessed 14 Aug 2020.

23. Halford C, Wallman T, Welin L, et al. Effects of self-rated health on sick leave, disability pension, hospital admissions and mortality. A population-based longitudinal study of nearly 15,000 observations among Swedish women and men. BMC Public Health. 2012;12:1103.

24. Noh JW, Chang Y, Park M, Kwon YD, Ryu S. Self-rated health and the risk of incident type 2 diabetes mellitus: A cohort study. Sci Rep. 2019;9:3697.

25. Waller Lidström $M$, Wennberg $P$, Lundqvist $R$, Forssén $A$, Waller $G$. Time trends of comparative self-rated health in adults aged 25-34 in the Northern Sweden MONICA study, 1990-2014. PLoS One. 2017;12:e0187896.

26. Clause-Verdreau AC, Audureau É, Leplège A. Contrasted trends in health-related quality of life across gender, age categories and work status in France, 1995-2016: repeated population-based cross-sectional surveys using the SF-36. 2019;73:65-72.

27. Lahelma E, Aittomaki A, Laaksonen M, Lallukka T. Cohort Profile: The Helsinki Health Study. Intl J Epidemiol. 2013;42:722-730.

28. Statistics Sweden. Available from:

http://www.statistikdatabasen.scb.se/GiftMedelalder/table/ Accessed 14 Aug 2020. 
Table 1. Descriptive characteristics of 38- and 50-year-old women in the Population Study of Women in Gothenburg regarding the assessments performed in 1980, 2004 and 2016, respectively $(n=1550)$. P values for trend over time.

\begin{tabular}{|c|c|c|c|c|c|c|c|c|}
\hline & \multicolumn{2}{|c|}{1980} & \multicolumn{2}{|c|}{2004} & \multicolumn{2}{|c|}{2016} & \multirow[b]{2}{*}{$\begin{array}{c}P \\
38 \text { years }\end{array}$} & \multirow[b]{2}{*}{$\begin{array}{c}P \\
50 \text { years }\end{array}$} \\
\hline & $\begin{array}{c}38 \text { years } \\
122 \mathrm{n}(\%) \\
\end{array}$ & $\begin{array}{c}50 \text { years } \\
355 \mathrm{n}(\%)\end{array}$ & $\begin{array}{l}38 \text { years } \\
207 \mathrm{n}(\%)\end{array}$ & $\begin{array}{l}50 \text { years } \\
293 \mathrm{n}(\%)\end{array}$ & $\begin{array}{c}38 \text { years } \\
263 \mathrm{n}(\%)\end{array}$ & $\begin{array}{c}50 \text { years } \\
310 \mathrm{n}(\%)\end{array}$ & & \\
\hline $\begin{array}{l}\text { Well-being poor } \\
(4-7)\end{array}$ & $46(38)$ & $161(46)$ & $48(24)$ & $101(35)$ & $92(35)$ & $109(36)$ & & \\
\hline $\begin{array}{l}\text { Well-being good } \\
(1-3)\end{array}$ & $76(62)$ & $193(54)$ & $152(76)$ & $188(65)$ & $168(65)$ & $197(64)$ & 0.69 & $<0.01$ \\
\hline \multicolumn{9}{|l|}{ Mental stress } \\
\hline Low & $95(78)$ & $293(83)$ & $109(55)$ & $134(47)$ & $94(36)$ & $157(51)$ & & \\
\hline Medium-high & $27(22)$ & $62(17)$ & $90(45)$ & $154(53)$ & $167(64)$ & $152(49)$ & $<0.01$ & $<0.01$ \\
\hline \multicolumn{9}{|l|}{ Socio-occupation } \\
\hline Low & $51(43)$ & $143(47)$ & $52(26)$ & $84(29)$ & $41(17)$ & $73(24)$ & & \\
\hline Medium & $57(48)$ & $129(43)$ & $100(49)$ & $145(51)$ & $118(48)$ & $145(48)$ & & \\
\hline High & $11(9)$ & $30(10)$ & $52(25)$ & $57(20)$ & $85(35)$ & $82(27)$ & $<0.01$ & $<0.01$ \\
\hline \multicolumn{9}{|l|}{ Smoking } \\
\hline Yes & $46(38)$ & 139 (39) & $23(11)$ & $67(23)$ & $23(9)$ & $37(12)$ & & \\
\hline No & $76(62)$ & $216(61)$ & $181(89)$ & $224(77)$ & $240(91)$ & $273(88)$ & $<0.01$ & $<0.01$ \\
\hline \multicolumn{9}{|l|}{$\mathrm{BMI}$} \\
\hline$<25$ & $100(83)$ & 209 (59) & $136(69)$ & $173(62)$ & $179(68)$ & $177(58)$ & & \\
\hline$\geq 25$ & $21(17)$ & $146(41)$ & $60(31)$ & $108(38)$ & $83(32)$ & $131(42)$ & 0.01 & 0.77 \\
\hline \multicolumn{9}{|l|}{ Leisure time } \\
\hline \multicolumn{9}{|l|}{ physical activity } \\
\hline Low (1) & $42(34)$ & $114(32)$ & $46(22)$ & $48(17)$ & $18(7)$ & $31(10)$ & & \\
\hline High (2-4) & $80(66)$ & $241(68)$ & $158(78)$ & 241 (83) & $244(93)$ & $278(90)$ & $<0.01$ & $<0.01$ \\
\hline
\end{tabular}


Table 2. Time, age and socio-economic position as separate predictors for poor well-being and high mental stress in all 38- and 50-year-old women (dependent variable). Logistic regression. Odds ratios (OR) with 95\% confidence intervals (CI).

\begin{tabular}{lcccc}
\hline & $\begin{array}{c}\text { Poor well-being } \\
\text { OR }(\mathrm{Cl})\end{array}$ & $\mathrm{p}$ & $\begin{array}{c}\text { High mental stress } \\
\text { OR }(\mathrm{Cl})\end{array}$ & $\mathrm{p}$ \\
\cline { 2 - 5 } & & & & \\
Time & $0.91(0.73-1.13)$ & 0.41 & $2.38(1.89-3.00)$ & $<0.01$ \\
Age & $1.45(0.90-1.49)$ & $\mathbf{0 . 0 5}$ & $0.80(0.61-1.05)$ & 0.11 \\
SEP & $2.00(1.31-3.04)$ & $<0.01$ & $1.02(0.76-1.37)$ & 0.89 \\
\hline
\end{tabular}


Table 3. Test of the association between poor well-being (scale 4-7) (outcome)/ high mental stress (outcome), and low socio-occupational group, defined as the exposed group, 1980, 2004 and 2016. Logistic regression. Odds ratios (OR) with 95\% confidence intervals (CI).

\begin{tabular}{|c|c|c|c|c|c|c|}
\hline & \multicolumn{6}{|c|}{ Low socio-occupational group } \\
\hline & \multicolumn{2}{|l|}{1980} & \multicolumn{2}{|l|}{2004} & \multicolumn{2}{|l|}{2016} \\
\hline & $\mathrm{OR}(\mathrm{Cl})$ & $p$ & $\mathrm{OR}(\mathrm{Cl})$ & $p$ & $\mathrm{OR}(\mathrm{Cl})$ & $\mathrm{p}$ \\
\hline \multicolumn{7}{|c|}{$\begin{array}{l}\text { Poor well-being } \\
\text { scale 4-7 }\end{array}$} \\
\hline $\begin{array}{l}\text { 38- and 50- } \\
\text { year-olds }\end{array}$ & $1.48(1.00-2.19)$ & 0.05 & $2.14(1.41-3.24)$ & $<0.01$ & $1.19(0.76-1.86)$ & 0.46 \\
\hline \multicolumn{7}{|l|}{$\begin{array}{l}\text { High mental } \\
\text { stress }\end{array}$} \\
\hline $\begin{array}{l}\text { 38- and 50- } \\
\text { year-olds }\end{array}$ & $0.96(0.58-1.58)$ & 0.87 & $1.00(0.68-1.49)$ & 0.99 & $1.00(0.64-1.56)$ & 0.99 \\
\hline
\end{tabular}




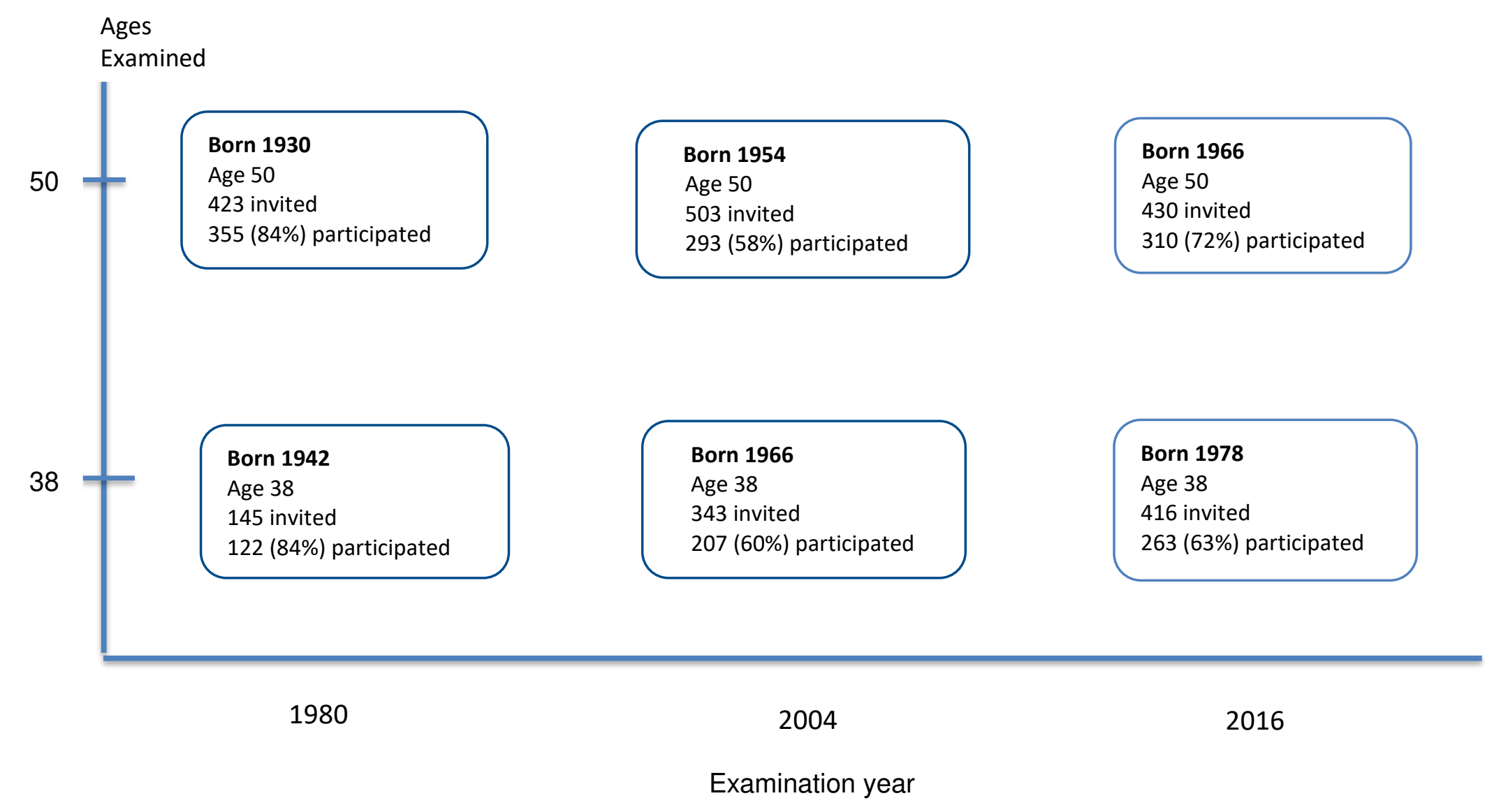

Figure 1. Description of the six 38- and 50-year-old cohorts examined in the Population Study of Women examinations in 1980, 2004 and 2016, respectively. Year of birth, number of invited women and number of women who participated in the respective examinations. 


\section{How do you experience your health situation (well-being)?}

1 Excellent, couldn't be better

$\square 2$

口 3

$\square 4$

$\square 5$

$\square 6$

$\square 7$ Very poor
Have you experienced any period of mental stress... (one month or more) and by stress we mean that you have been: Irritable, Tense, Nervous, Anxious, Afraid, Anguished and/or Sleepless...connected with concern for: Your work, Your health, Your family, Conflict with the people around you (at home, at work) and/or another cause.

$\square$ never experienced any period of stress

$\square$ experienced a period of stress

$\square$ experienced a period of stress during the last 5 years

$\square$ experienced several periods of stress during the last 5 years

$\square$ living under constant stress during the last year

$\square$ living under constant stress during the last 5 years

Figure 2. Questionnaire items concerning well-being and mental stress and their response categorisation in the Population Study of Women in Gothenburg. 


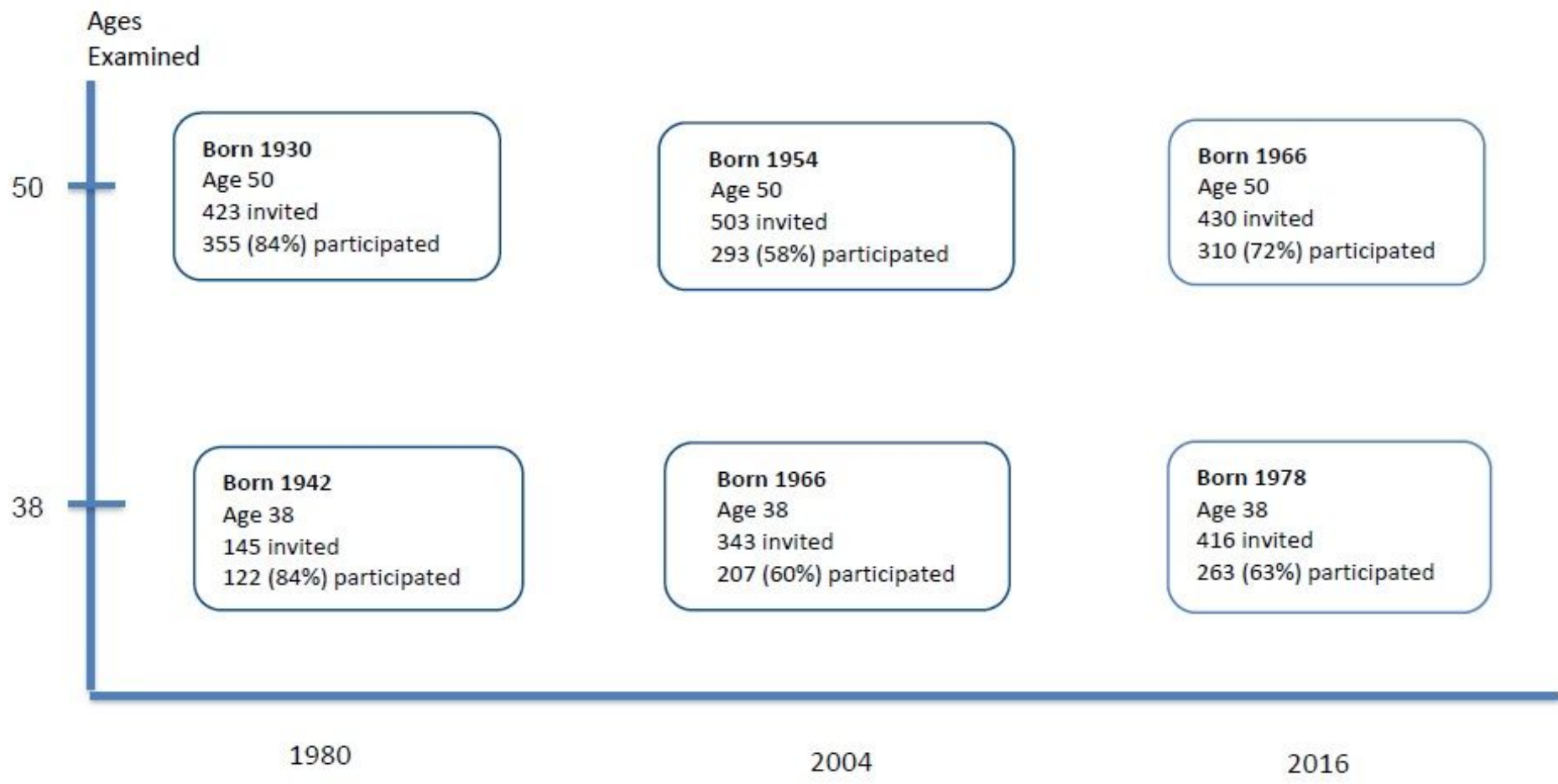

Examination year

\section{Figure 1}

Description of the six 38- and 50-year-old cohorts examined in the Population Study of Women examinations in 1980, 2004 and 2016, respectively. Year of birth, number of invited women and number of women who participated in the respective examinations.

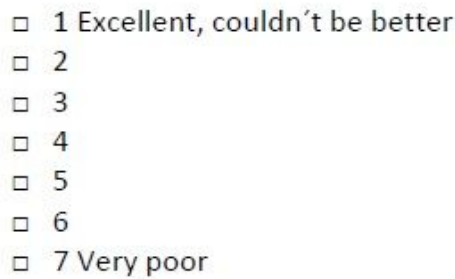

\section{Figure 2}

Questionnaire items concerning well-being and mental stress and their response categorisation in the Population Study of Women in Gothenburg.
Have you experienced any period of mental stress... (one month or more) and by stress we mean that you have been: Irritable, Tense, Nervous, Anxious, Afraid, Anguished and/or Sleepless...connected with concern for: Your work, Your health, Your family, Conflict with the people around you (at home, at work) and/or another cause.

$\square$ never experienced any period of stress

$\square$ experienced a period of stress

$\square$ experienced a period of stress during the last 5 years

$\square$ experienced several periods of stress during the last 5 years

$\square$ living under constant stress during the last year

$\square$ living under constant stress during the last 5 years 